\title{
WEAR OF TURNING TOOL DURING MACHINING OF STEELS USED IN SURGICAL INSTRUMENTS
}

\author{
Magdalena Zawada-Michalowska ${ }^{1}$, Pawel Piesko ${ }^{1}$, Jerzy Jozwik $^{1}$, Andrzej Lukaszewicz ${ }^{2}$ \\ ${ }^{1}$ Lublin University of Technology, Poland; ${ }^{2}$ Bialystok University of Technology, Poland \\ m.michalowska@pollub.pl,p.piesko@pollub.pl,j.jozwik@pollub.pl, a.lukaszewicz@pb.edu.pl
}

\begin{abstract}
The paper presents an assessment of the wear rate of turning tool blades during machining of steels applied in medical industry. The subjects of the research were stainless steels X20Cr13 (1.4021) and X8CrNiS18-9 (1.4305) used in production of surgical instruments. An experiment was carried out to assess the wear of multi-edge turning inserts with CVD coatings (Pafana CNMG 120408 ZSZ and Sandvik CNMA 1204 12-KR 3205), and an uncoated turning insert (Sandvik CNGA 120408 T0102 WG 650). The wear was measured by the direct wear indicator $V B_{C}$. On the basis of the results obtained for both X20Cr13 and X8CrNiS18-9, it was found that the Pafana CNMG 120408 ZSZ turning insert had the best wear resistance during machining. The cutting path of Pafana CNMG 120408 ZSZ was about $25 \%$ longer than Sandvik CNMA 1204 12-KR 3205 and about $300 \%$ longer than Sandvik CNGA 120408 T0102 WG 650. It was also found that each turning insert revealed a linear wear.
\end{abstract}

Keywords: tool blade durability, tool blade wear, turning, steel, surgical instruments.

\section{Introduction}

Surgical instruments are a group of medical devices. It covers a wide range of tools that differ in terms of functionality and geometricity. The materials from which surgical instruments are manufactured have to comply with stringent requirements. The expectations are defined in suitable usable features, high mechanical properties, corrosion resistance and extremely good biocompatibility [1-5]. New surgical robots use many types of instruments [6-9].

Widely used materials for surgical instruments are high-quality grades of stainless steel, especially austenitic and martensitic ones. These steel grades exhibit high resistance to air, moisture, and weak solutions of salts and acids. Corrosion resistance is endowed to a steel material by its feasibility to be passivated, which directly depends on the chemical composition. Passivation gives an oxide layer, which protects its substrate against ambient conditions and can replenish itself. In stainless steel, this effect is caused by chromium as an alloy additive, and only when its content is $10.5 \%$ or higher. With the chromium content corrosion resistance grows [10].

Stainless steel grades vary in machinability. Ferritic and martensitic steels are relatively well machinable, while high-alloy austenitic grades exhibit a very poor machinability. Machinability of these steels depends first on high tendency to strain hardening, creating a build-up edge, low heat conductivity and capacity, accelerated cutting edge wear, and chip control problems. It is then critical to choose the correct machining parameters, materials and geometry of tools. CAD/CAM systems are recommended to use for modelling 3D virtual product and for generating a cutting path [11-15].

Cemented carbide tools are commonly used for machining of stainless steel workpieces. Additionally, they are protected with coatings to inhibit wear. Cutting tools made from cemented carbide with multi-layer coatings (with up to several dozen coating layers) have been increasingly popular. Another trend in cutting tools is their preservation with single-layer coatings of polycrystalline diamond (PCD) or common boron nitride (CBN). The protective coatings can be deposited to the working surfaces of cutting tools with two methods: CVD (Chemical Vapour Deposition) or PVD (Physical Vapour Deposition) [16-17].

The cutting ability and operation of cutting tools are largely affected by the protective coating material. Protective coatings increase the machining efficiency (which means higher technological parameters) and extend the cutting edge durability [18-19].

Stainless steel machining is recommended to be done with multi-edge tool inserts, the wear of which should be monitored. The wear of a cutting edge is determined by its loss of cutting ability properties over time. This process is very complex and defined by many factors. Wear occurs near the cutting edge over the flank face and/or the tool face. Several types of wear exist: abrasive, chemical, adhesive, thermal, and mechanical. During stainless steel machining, the following wear phenomena 
occur very often: focused cutting edge wear, $V B_{N}$; cutting edge plastic deformation; and relatively soon accelerated chase widening [20-23].

The cutting tool edge wear rate is determined with direct and indirect indicators. Indirect ratio defines changes in physical quantities caused by wear, including reduction in dimensional and shape accuracy, cutting force increase, reduction in surface quality (a lot of scientific papers focus on the study of surface roughness parameters), burr formation, cutting temperature increase, and growth in vibration and noise during machining [24-31]. The wear of machining tools is particularly important manufacturing elements with free-form surfaces [32-36] as well as in mould components production [37-42].

\section{Materials and methods}

The objective of this work was to assess the wear rate of turning tools during machining of stainless steel grades for medical instruments.

Experimental turning of the tested grades was done with a DMG MORI CTX450 turning centre with the Sinumeric 840D control system. The specimens were fabricated from X20Cr13 (1.4021) and X8CrNiS18-9 (1.4305) steel grades. X20Cr13 stainless steel has martensitic structure, while $\mathrm{X} 8 \mathrm{CrNiS} 18-9$ is austenitic steel.

Turning was carried out with the following turning inserts:

- CNMG 120408 ZSZ (multi-edge carbide insert of Pafana, coated with Ti(C,N) + Al2O3, CVD);

- CNMA 1204 12-KR 3205 (multi-edge carbide insert of Sandvik, coated with $\mathrm{Ti}(\mathrm{C}, \mathrm{N})+\mathrm{Al} 2 \mathrm{O} 3+\mathrm{TiN}, \mathrm{CVD})$,

- CNGA 120408 T0102 WG 650 (multi-edge ceramic insert of Sandvik, uncoated).

The specimens were fabricated into cylinders $12 \mathrm{~mm}$ in diameter. The specimens were fabricated by turning at a cutting length $l=150 \mathrm{~mm}$ and with fixed cutting parameters: cutting depth $a_{p}=1 \mathrm{~mm}$, cutting speed $v_{c}=75 \mathrm{~m} / \mathrm{min}$, and feed $f=0.12 \mathrm{~mm} / \mathrm{rev}$. The machining program was developed in CAM NX 11.

The wear rate was analysed and defined as $V B_{C}$, the width of flank wear land in the corner area (according to PN-ISO 3685:1996, Tool-life testing with single-point turning tools). The conditions of the insert cutting edges were evaluated before machining and after each machining test under the Keyence VHX-5000 digital microscope. The turning insert wear was monitored after each tool pass. The testing was continued until catastrophic failure of the tested turning tool.

\section{Results and discussion}

Fig. 1 shows the images of the successive wear stages on the Pafana CNMG 120408 ZSZ tool insert during machining of X8CrNiS18-9 stainless steel. Each image was captured after every $5^{\text {th }}$ pass.

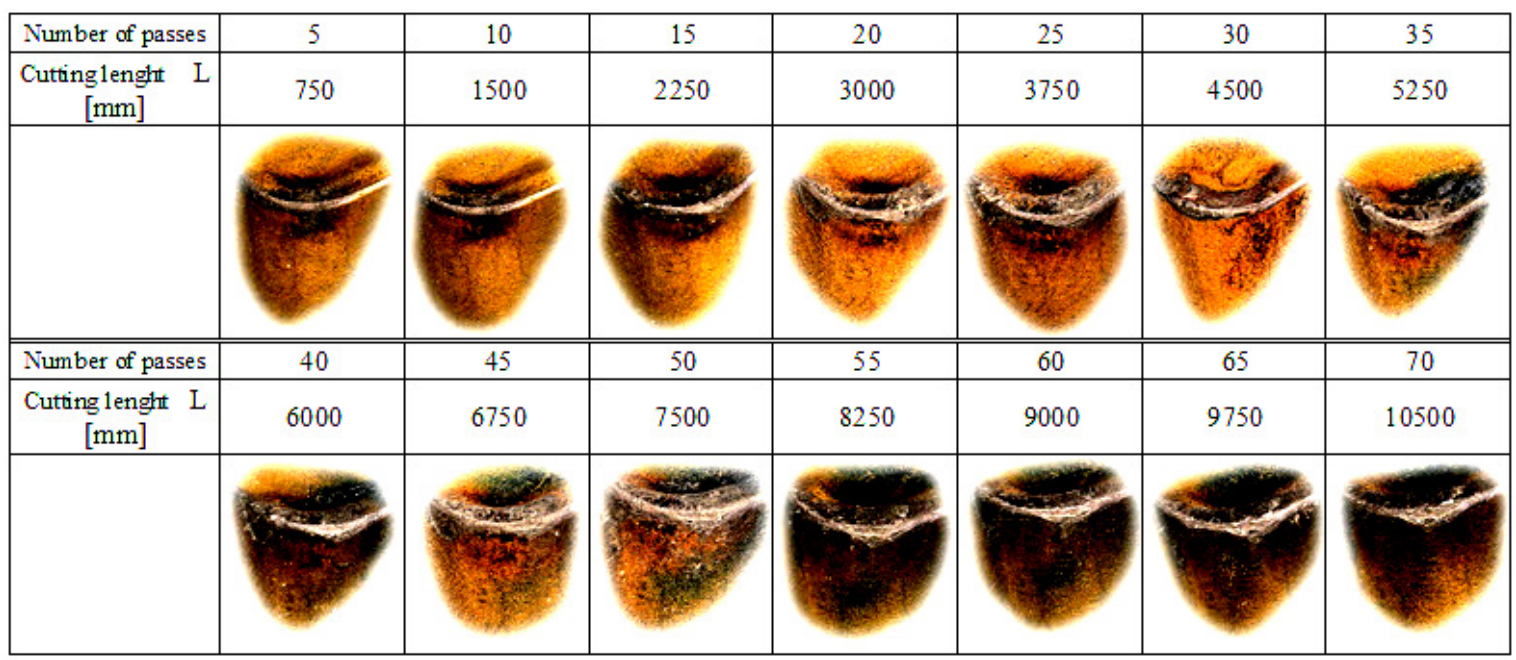

Fig. 1. Images of successive wear stages on Pafana CNMG $120408 \mathrm{ZSZ}$ tool tip during machining of X8CrNiS18-9 stainless steel (each image was captured after every fifth pass) 
Given a very high number of test results, the direct wear ratio $V B_{C}$ was presented for every fifth turning tool pass. Fig. 2 shows the trend of $V B_{C}$ as a function of the cutting path length $L$ during machining of X20Cr13 stainless steel with the following turning inserts: CNMG $120408 \mathrm{ZSZ}$, CNMA 1204 12-KR 3205, and CNGA 120408 T0102 WG 650.

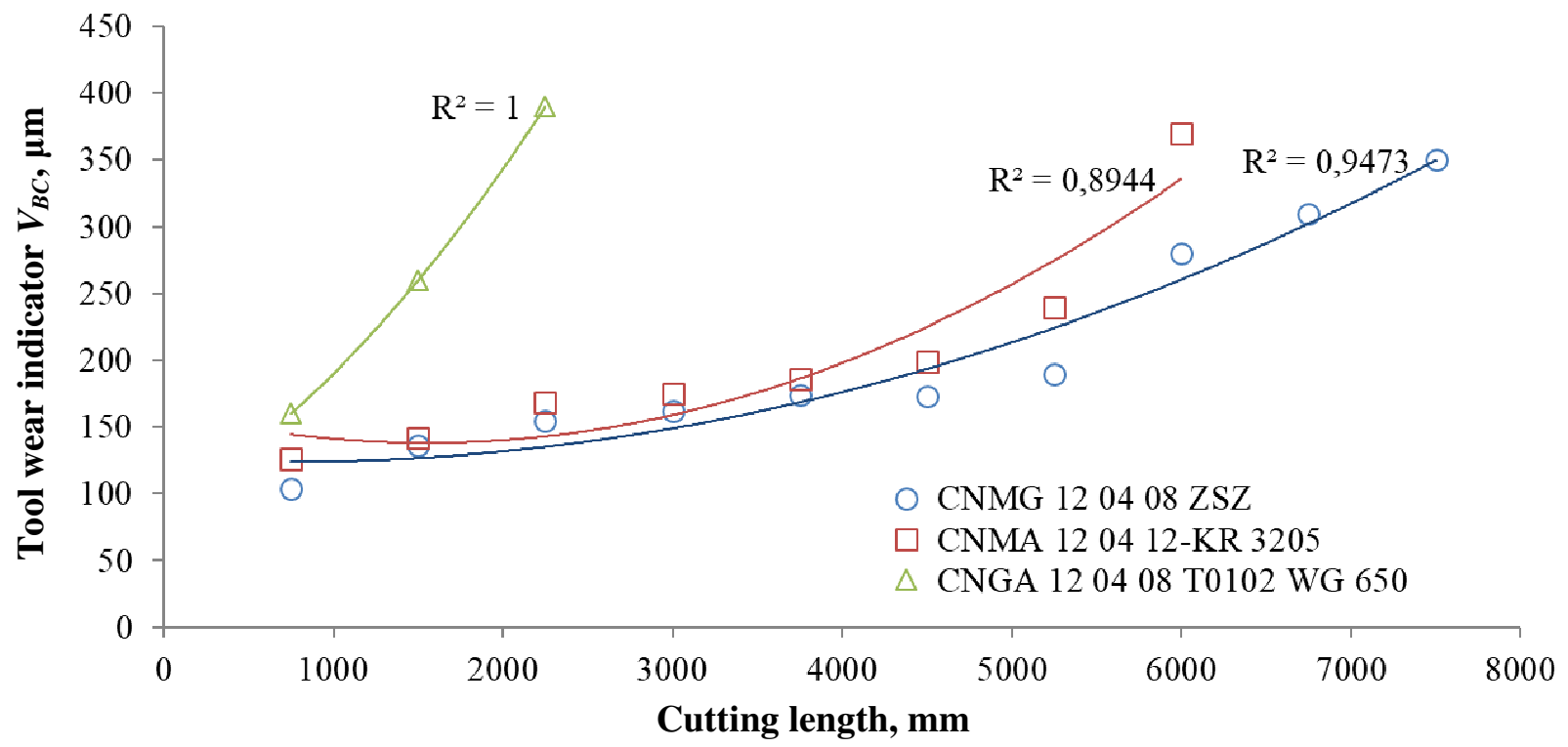

Fig. 2. Trend of tool wear indicator $V_{B C}$ as function of cutting path length $L$ during machining of $\mathrm{X} 20 \mathrm{Cr} 13$ stainless steel

The test results for the width of the flank wear land $V B_{C}$ during machining of $\mathrm{X} 20 \mathrm{Cr} 13$ stainless steel grade were approximated with a second-degree polynomial function. Equation (1) shows the trend of $V B_{C}$ for the Pafana CNMG $120408 \mathrm{ZSZ}$ tool insert. Equation (2) presents the trend of $V B_{C}$ for the Sandvik CNMA 1204 12-KR 3205 tool insert. Equation (3) shows the trend of $V B_{C}$ for the Sandvik CNGA 120408 T0102 WG 650 tool insert.

$$
\begin{gathered}
V B_{c}=5 \cdot 10^{-6} L^{2} k_{2}-0.0075 L k_{1}+126.82 k_{0} \\
V B_{c}=10^{-5} L^{2} k_{2}-0.031 L k_{1}+162.09 k_{0} \\
V B_{c}=3 \cdot 10^{-5} L^{2} k_{2}-0.733 L k_{1}+90 k_{0}
\end{gathered}
$$

where $k_{i}$ are the polynomial unit factors being the unit ordinals: $k_{2}=1 \mu \mathrm{m} \cdot \mathrm{mm}^{2}, k_{1}=1 \mu \mathrm{m} \cdot \mathrm{mm}$, $k_{0}=1 \mu \mathrm{m}$.

The trend of $V B_{C}$ as a function of the cutting path length $L$ during machining of X8CrNiS18-9 stainless steel with the CNMG 120408 ZSZ, CNMA 1204 12-KR 3205 and CNGA 120408 T0102 WG 650 tool inserts is shown in Fig. 3.

The test results for the width of the flank wear land $V B_{C}$ during machining of X8CrNiS18-9 stainless steel grade were approximated with a second-degree polynomial function. Equation (4) shows the trend of $V B_{C}$ for the Pafana CNMG $120408 \mathrm{ZSZ}$ tool insert. Equation (5) presents the trend of $V B_{C}$ for the Sandvik CNMA 1204 12-KR 3205 tool insert. Equation (6) shows the trend of $V B_{C}$ for the Sandvik CNGA 120408 T0102 WG 650 tool insert.

$$
\begin{gathered}
V B_{c}=-3 \cdot 10^{-6} L^{2} k_{2}+0.072 L k_{1}+114 k_{0} \\
V B_{c}=2 \cdot 10^{-6} L^{2} k_{2}-0.0018 L k_{1}+130.43 k_{0} \\
V B_{c}=10^{-6} L^{2} k_{2}-0.0107 L k_{1}+101.85 k_{0}
\end{gathered}
$$

where $k_{i}$ are the polynomial unit factors being the unit ordinals: $k_{2}=1 \mu \mathrm{m} \cdot \mathrm{mm}^{2}, k_{1}=1 \mu \mathrm{m} \cdot \mathrm{mm}$, $k_{0}=1 \mu \mathrm{m}$.

The analysis of the direct wear ratio $V B_{C}$ revealed that each tool insert had wear progression approximate to linear. The fastest wear was found in the CNGA 120408 T0102 WG 650 turning 
insert, which due to its material was not insensitive to vibrations of the machine tool/holder/workpiece/tool system.

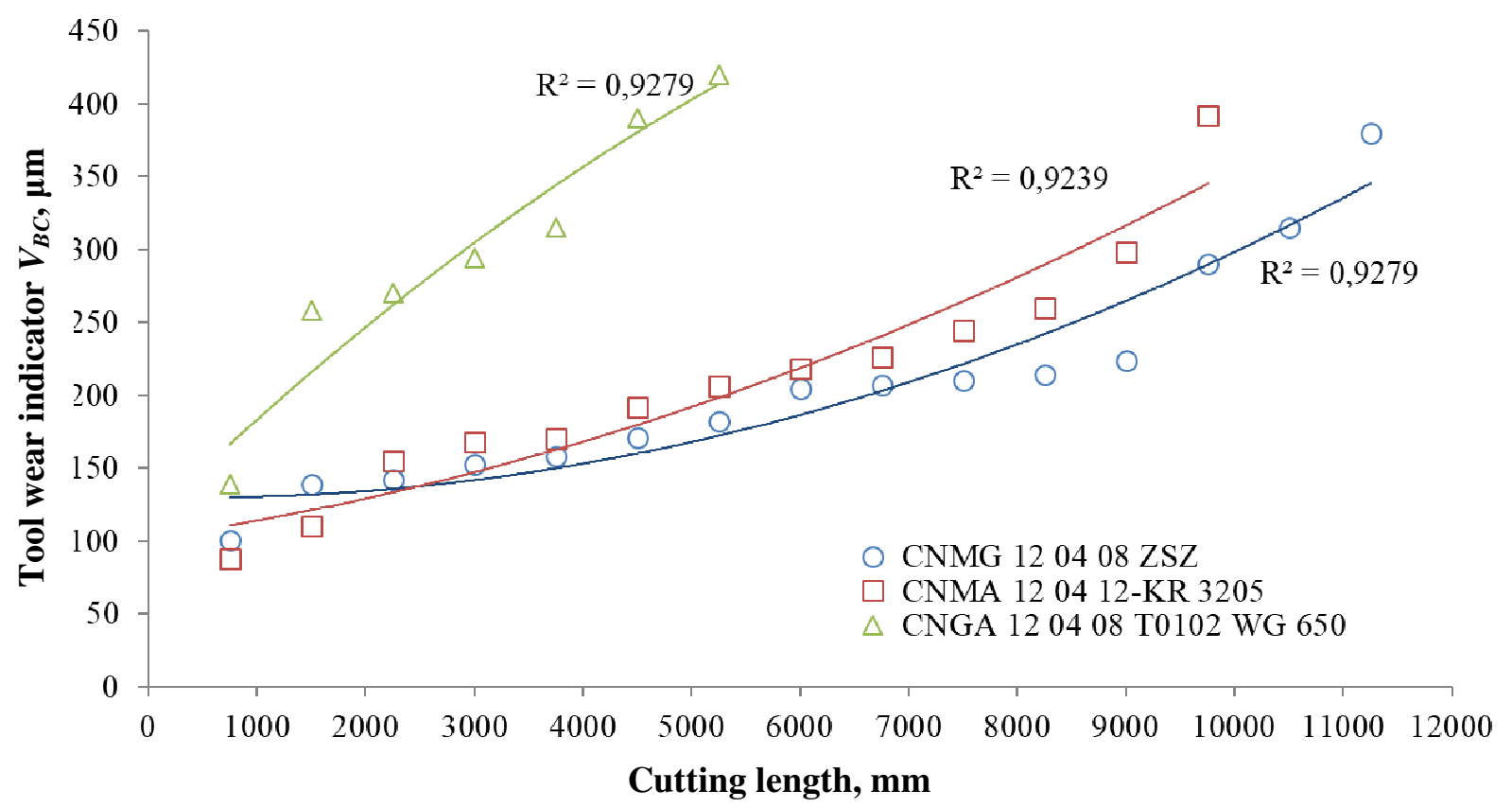

Fig. 3. Trend of tool wear indicator $V_{B C}$ as function of cutting path length $L$ during machining of $\mathrm{X8CrNiS18-9}$ stainless steel

\section{Conclusions}

The experimental test results allowed the following conclusions:

1. X8CrNiS18-9 stainless steel grade had better machinability than X20Cr13. While the former was austenitic, its sulphur content favoured better machinability. This was confirmed with a relatively longer cutting path when machining $\mathrm{X} 8 \mathrm{CrNiS18-9.} \mathrm{Depending} \mathrm{on} \mathrm{the} \mathrm{tested} \mathrm{tool} \mathrm{insert,} \mathrm{the}$ overall cutting path until the catastrophic failure of the tool insert was longer between $45 \%$ and $175 \%$ than the overall cutting path when machining X20Cr13.

2. In both stainless steel grades tested herein, the cutting path of Pafana CNMG $120408 \mathrm{ZSZ}$ was about $25 \%$ longer than of Sandvik CNMA 1204 12-KR 3205 and about $300 \%$ longer than Sandvik CNGA 120408 T0102 WG 650.

3. Considering the durability of replaceable multi-edge tool inserts, it is recommended to machine the tested stainless steel grades with Pafana CNMG 120408 ZSZ.

\section{References}

[1] Scheinberg N., et al. A systematic approach to improve the reprocessing of surgical instruments. In: Advances in Human Factors and Ergonomics in Healthcare, Cham, Springer, 2017, pp. 275286.

[2] Costa D.D.M., et al. Evaluation of stainless steel surgical instruments subjected to multiple use/processing. Infection, Disease and Health, vol. 23, issue 1, 2018, pp. 3-9.

[3] Madan A.K., Olson W.A., Witt D.A. Surgical blades with fatigue resistant properties. U.S. Patent Application No. 15/062,577.

[4] Zhang H., et al. A minimally invasive surgical instrument of hand-held with self-locking. In: BIBE 2018; International Conference on Biological Information and Biomedical Engineering, VDE, 2018. pp. 1-6.

[5] Lopes L.K.O., et al. Complex design of surgical instruments as barrier for cleaning effectiveness, favouring biofilm formation. Journal of Hospital Infection, 2018, DOI: 10.1016/j.jhin.2018.11.001

[6] Bednar F., Hogg M.E., Zeh H.J., Zureikat, A.H. Robotic-assisted distal pancreatectomy. In: The SAGES Manual of Robotic Surgery, Cham, Springer, 2018, pp. 253-264. 
[7] Doulamis, I.P., et al. The role of robotics in cardiac surgery: a systematic review. Journal of robotic surgery, 2018, pp. 1-12.

[8] Le H.M., et al. Design and modelling of a variable stiffness manipulator for surgical robots. Mechatronics, vol. 53, 2018, pp. 109-123.

[9] Trochimczuk R., et al. Finite element method stiffness analysis of a novel telemanipulator for minimally invasive surgery. Simulation: Transactions of the Society for Modeling and Simulation International, 2019, DOI: 10.1177/0037549719835920.

[10] Corrêa J.G., Schroeter R.B., Machado A.R. Tool life and wear mechanism analysis of carbide tools used in the machining of martensitic and supermartensitic stainless steels. Tribology International, vol. 105, 2017, pp. 102-117.

[11] Alabdullah M., Polishetty A., Littlefair G. Impacts of wear and geometry response of the cutting tool on machinability of super austenitic stainless steel. International Journal of Manufacturing Engineering, vol. 2016, 2016, pp. 1-9.

[12] Diniz A.E., Machado Á.R., Corrêa J.G. Tool wear mechanisms in the machining of steels and stainless steels. International Journal of Advanced Manufacturing Technology, vol. 87, issue 9-12, 2016, pp. 3157-3168.

[13] Korkmaz M.E., Günay M. Finite element modelling of cutting forces and power consumption in turning of AISI 420 martensitic stainless steel. Arabian Journal for Science and Engineering, vol. 43, 2018, pp. 4863-4870.

[14] Łukaszewicz A., Skorulski G., Szczebiot R. The main aspects of training in the field of computeraided techniques $(\mathrm{CAx})$ in mechanical engineering. Proceedings of 17th International Scientific Conference on Engineering for Rural Development, May 23-25, 2018, Jelgava, Latvia, pp. 865870.

[15] Miatliuk K., Łukaszewicz A., Siemieniako F. Coordination method in design of forming operations of hierarchical solid objects. Proceedings of International Conference on Control, Automation and Systems: ICCAS'2008, Oct. 14-17, 2008, Seoul, South Korea, pp. 2724-2357.

[16] Polishetty A., Alabdullah M., Littlefair G. Tool wear analysis due to machining in super austenitic stainless steel. Proceedings of the 3rd International Conference on Mechatronics and Mechanical Engineering (ICMME 2016), October 21-23, 2016, Shanghai, China, vol. 95, pp. 1-4.

[17] Sathishkumar S.D., Rajmohan T. Multi-response optimization of machining parameters in CNC turning of AISI 3161 stainless steel using MQL nano fluids. IOP Conference Series: Materials Science and Engineering, vol. 390, issue 1, pp. 1-9.

[18] Ahmed Y.S., Paiva J.M., Covelli D., Veldhuis S.C. Investigation of coated cutting tool performance during machining of super duplex stainless steels through $3 \mathrm{D}$ wear evaluations. Coatings, vol. 7, issue 8, 2017, pp. 1-15.

[19] Kuczmaszewski J., Pieśko P., Zawada-Michałowska M. Carbide milling cutter blades durability during machining of Al-Si casting alloy. Multidisciplinary Aspects of Production Engineering, vol. 1, 2018, pp. 169-175.

[20] Gziut O., Kuczmaszewski J., Zagórski I. Surface quality assessment following high performance cutting of AZ91HP magnesium alloy. Management and Production Engineering, vol. 6, issue 1, 2015, pp. 4-9.

[21] Kuczmaszewski J., Zaleski K., Matuszak J., Pałka T., Mądry J. Studies on the effect of mill microstructure upon tool life during slot milling of TI6AL4V alloy parts. Maintenance and Reliability, vol. 19, issue 4, 2017, pp. 590-596.

[22] Kuczmaszewski J., Pieśko P. Wear of milling cutters resulting from high silicon aluminium alloy cast AlSi21CuNi machining. Maintenance and Reliability, vol. 16, issue 1, 2014, pp. 37-41.

[23] Liew W.Y.H., Ngoi B.K.A., Lu Y.G. Wear characteristics of PCBN tools in the ultra-precision machining of stainless steel at low speeds. Wear, vol. 254, issue 3-4, 2003, pp. 265-277.

[24] Józwik J. Evaluation of Tribological Properties and condition of Ti6Al4V titanium alloy surface. Tehnički vjesnik, vol. 25, issue 1, 2018, pp. 170-175.

[25] Józwik J., Wac-Włodarczyk A., Michałowska J., Kłoczko M. Monitoring of the noise emitted by machine tools in industrial conditions. Journal of Ecological Engineering, vol. 19, issue 1, 2018, pp. 83-93.

[26] Królczyk G., Gajek M., Legutko S. Effect of the Cutting Parameters Impact on Tool Life in Duplex Stainless Steel Turning Process. Tehnicki Vjesnik, vol. 20, issue 4, 2013, pp. 587-592. 
[27] Barsukov V.V., et al. Express evaluation method of internal friction parameters in molding material briquettes. Journal of Friction and Wear, Vol. 38, issue 1, 2017, pp. 71-76.

[28] Królczyk G., Nieslony P., Legutko S. Determination of tool life and research wear during duplex stainless steel turning. Archives of Civil and Mechanical Engineering, vol. 15, issue 2, 2015, pp. 347-354.

[29] Węgrzyn T., Piwnik J., Wszołek Ł., Tarasiuk W. Shaft wear after surfacing with micro-jet cooling. Archives of Metallurgy and Materials, vol. 60, issue 4, 2015, pp. 2625-2630.

[30] Łukaszewicz A. Nonlinear numerical model of heat generation in the rotary friction welding. Journal of Friction and Wear, vol. 39, issue 6, 2018, pp. 476-482.

[31] Pytka J., Tarkowski P., Budzyński P., Józwik J. method for testing and evaluating grassy runway surface. Journal of Aircraft, vol. 54, issue 1, 2017, pp. 229-234.

[32] Łukaszewicz A., Miatluk K. Reverse engineering approach for object with free-form surfaces using standard surface-solid parametric CAD system. Solid State Phenomena, vols. 147-149, 2009, pp. 706-711.

[33] Poniatowska M., Werner A. Fitting spatial models of geometric deviations of free-form surfaces determined in coordinate measurements. Metrology and Measurement Systems, vol. 17, issue 4, 2010, pp. 599-610.

[34] Poniatowska M., Werner A., Simulation tests of the method for determining a cad model of freeform surface deterministic deviations, Metrology and Measurement Systems, vol. 19, issue 1, 2012, pp. 151-158.

[35] Scandiffio I., Diniz A.E., de Souza A.F. Evaluating surface roughness, tool life, and machining force when milling free-form shapes on hardened AISI D6 steel. The International Journal of Advanced Manufacturing Technology, vol. 82. issue 9-12, 2016, pp 2075-2086.

[36] Scandiffio I., Diniz A.E., de Souza A.F. The influence of tool-surface contact on tool life and surface roughness when milling free-form geometries in hardened steel. The International Journal of Advanced Manufacturing Technology, vol. 92, issue 1-4, 2017, pp. 615-626.

[37]Farhat Z.N. Wear mechanism of CBN cutting tool during high-speed machining of mold steel. Materials Science and Engineering: A, vol. 361, issue 1-2, 2003, pp. 100-110.

[38] Lahiff C., Gordon S., Phelan P. PCBN tool wear modes and mechanisms in finish hard turning. Robotics and Computer-Integrated Manufacturing, vol. 23, issue 6, 2007, pp. 638-644.

[39] Schueler G.M., Engmann J., Marx T., Haberland R., Aurich J.C. Burr formation and surface characteristics in micro-end milling of titanium alloys. In: Burrs-analysis, control and removal, Berlin, Springer, 2010, pp. 129-138.

[40] Werner A. Method for enhanced accuracy in machining curvilinear profiles on wire-cut electrical discharge machines, Precision Engineering, vol. 44, 2016, pp. 75-80.

[41] Mircheski I., Łukaszewicz A., Szczebiot R. Injection process design for manufacturing of bicycle plastic bottle holder using CAx tools, Procedia Manufacturing, vol. 32, 2019, pp. 68-73.

[42] Mircheski I., et al. Application of CAx system for design and analysis of plastic parts manufactured by injection moulding. Proceedings of 18th International Scientific Conf. on Engineering for Rural Development, May 22-24, 2019, Jelgava, Latvia, pp. 1755-1760. 